\title{
A Novel Composite Material Designed from FeSi Powder and $\mathrm{Mn}_{0.8} \mathrm{Zn}_{0.2} \mathrm{Fe}_{2} \mathrm{O}_{4}$ Ferrite
}

\author{
Magdalena Streckova, ${ }^{1}$ Radovan Bures, ${ }^{1}$ Maria Faberova, ${ }^{1}$ Pavel Kurek, ${ }^{1}$ Pavla Roupcova, \\ Hynek Hadraba, ${ }^{3}$ Vladimir Girman, ${ }^{4}$ and Jozef Strecka ${ }^{4}$
}

\author{
${ }^{1}$ Institute of Materials Research, Slovak Academy of Sciences, Watsonova 47, 04001 Košice, Slovakia \\ ${ }^{2}$ Institute of Physics of Materials ASCR v.v.i., Zizkova 22, 61662 Brno, Czech Republic \\ ${ }^{3}$ CEITEC IPM, Institute of Physics of Materials ASCR, Zizkova 513/22, 61662 Brno, Czech Republic \\ ${ }^{4}$ Institute of Physics, Faculty of Science, Pavol Jozef Šafárik University, Park Angelinum 9, 04001 Košice, Slovakia
}

Correspondence should be addressed to Jozef Strecka; jozef.strecka@upjs.sk

Received 20 January 2015; Revised 4 April 2015; Accepted 4 April 2015

Academic Editor: Chi-Wai Chow

Copyright (C) 2015 Magdalena Streckova et al. This is an open access article distributed under the Creative Commons Attribution License, which permits unrestricted use, distribution, and reproduction in any medium, provided the original work is properly cited.

A design of the novel microcomposite material composed of spherical FeSi particles and $\mathrm{Mn}_{0.8} \mathrm{Zn}_{0.2} \mathrm{Fe}_{2} \mathrm{O}_{4}$ ferrite is reported together with a characterization of basic mechanical and electrical properties. The sol-gel autocombustion method was used for a preparation of $\mathrm{Mn}_{0.8} \mathrm{Zn}_{0.2} \mathrm{Fe}_{2} \mathrm{O}_{4}$ ferrite, which has a spinel-type crystal structure as verified by XRD and TEM analysis. The final microcomposite samples were prepared by a combination of the traditional PM compaction technique supplemented with unconventional microwave sintering process of the prepared green compacts. The composition and distribution of the secondary phase formed by the spinel ferrite were examined by SEM. It is demonstrated that the prepared composite material has a tight arrangement without any significant porosity, which manifests itself through superior mechanical properties (high mechanical hardness, Young modulus, and transverse rupture strength) and specific electric resistivity compared to the related composite materials including resin as the organic binder.

\section{Introduction}

Soft magnetic composites (SMCs), which are of technological relevance in electromagnetic applications, can be described as ferromagnetic powder particles surrounded by an electrical insulating film [1]. It is well known that the core/shell particles can be processed by powder metallurgy (PM) methods. PM technologies are indeed able to produce SMCs with a high enough density and sufficiently stable mechanical properties, whereas an insulating layer between magnetic powder particles ensures a high electric resistivity that minimizes the overall magnetic losses [2]. The main advantage of SMCs prepared by PM methods with respect to laminated soft magnetic materials lies in their unique magnetic properties such as an isotropic three-dimensional ferromagnetic behavior, low eddy current losses, and relatively lower total core losses at medium and high frequencies [3, 4]. SMCs with superior magnetic properties are guaranteed by a choice of suitable soft magnetic material serving as a core and convenient insulating material serving as a coating. A lot of efforts have been devoted to a preparation of SMCs composed of different ferromagnetic base materials (Fe, Permalloy, Vitroperm, FeSi, etc.) and different hybrid organic resins (mostly of phenol-formaldehyde type) used as an insulating coating $[5,6]$. However, it is worthwhile to remark that a thermal treatment of these materials is strictly limited by a thermal resistance of the insulating organic material, which is inadequate in order to remove plastic deformations created during a preparation of green compacts [3]. In this regard, another promising way in order to produce SMCs with excellent properties consists in using spinel ferrites as a coating with an extremely high electric resistivity and almost zero eddy current losses in alternating magnetic fields, which will not basically affect the magnetic characteristics of metal cores (high magnetic flux density and low coercive force) [7]. In general, the ferrites are metal oxides containing divalent and trivalent metal ions. The spinel-type ferrites with 
the general formula $\mathrm{MFe}_{2} \mathrm{O}_{4}$ ( $\mathrm{M}$ is divalent metal ion, e.g., $\mathrm{Ni}^{2+}, \mathrm{Mn}^{2+}, \mathrm{Zn}^{2+}$, etc.) involve two sites, namely, tetrahedral sites $\mathrm{A}$ and octahedral sites $\mathrm{B}$. According to a distribution of the divalent metal ions $\mathrm{M}^{2+}$ between tetrahedral and octahedral sites one recognizes two different types of the ferrites: the normal spinels $\left[\mathrm{M}^{2+}\right]_{\mathrm{A}}\left[\mathrm{Fe}^{3+} \mathrm{Fe}^{3+}\right]_{\mathrm{B}} \mathrm{O}_{4}$ in which the divalent metal ions $\mathrm{M}^{2+}$ occupy the tetrahedral sites and the trivalent $\mathrm{Fe}^{3+}$ ions occupy the octahedral sites and, respectively, the inverse spinels $\left[\mathrm{Fe}^{3+}\right]_{\mathrm{A}}\left[\mathrm{M}^{2+} \mathrm{Fe}^{3+}\right]_{\mathrm{B}} \mathrm{O}_{4}$ in which the octahedral sites are occupied in part by the divalent metal ions $\mathrm{M}^{2+}$ and in part by the trivalent $\mathrm{Fe}^{3+}$ ions in contrast with the tetrahedral sites occupied exclusively by the trivalent $\mathrm{Fe}^{3+}$ ions [8]. Note, furthermore, that it is possible to control to a certain extent basic magnetic characteristics of spinel-type ferrites by changing the type of divalent cations [9], the size and shape of nanoparticles [10-12], which also have fundamental impact on a chemical composition and crystal structure $[13,14]$.

$\mathrm{Mn}_{x} \mathrm{Zn}_{1-x} \mathrm{Fe}_{2} \mathrm{O}_{4}$ ferrites belong to the most versatile ferrites among the inverse spinel ferrites due to their promising magnetic properties like high saturation magnetization, high magnetic permeability, high electrical resistance, and biocompatibility $[15,16]$. Up to date, the MnZn ferrites have been widely used in the field of electronic and electromagnetic devices [17-19]. Iron, zinc, and manganese are not only the main components of the MnZn ferrites, but they are also the main components of spent alkaline batteries. It is noteworthy that Yang et al. have developed a novel way to recycle spent alkaline batteries using a combination of sol-gel autocombustion and microwave digestion methods producing a powder of MnZn ferrite [20]. The microwaveassisted technique is environmentally friendly and economic low-cost method for a synthesis of ferrites [21,22]. To the best of our knowledge, the combination of sol-gel autocombustion method used for a preparation of the MnZn ferrite with the microwave-assisted sintering process of the composite samples has been not reported yet and it is therefore the main subject of the present work.

In this work, our particular attention will be focused on a design of perspective class of new SMCs based on spherical FeSi particles serving as a core and the inverse spinel ferrite $\mathrm{Mn}_{0.8} \mathrm{Zn}_{0.2} \mathrm{Fe}_{2} \mathrm{O}_{4}$ serving as a coating. The $\mathrm{MnZn}$ ferrite was synthesized by the sol-gel autocombustion method. The coating process was carried out immediately after gel creation and the autocombustion process run in a presence of the ferromagnetic FeSi particles. The crystal structure of $\mathrm{MnZn}$ ferrite was verified by TEM analysis. The coating deposited on spherical FeSi particles and the distribution of ferrite in the final microcomposite $\mathrm{FeSi} / \mathrm{MnZnFe} \mathrm{O}_{4}$ samples was investigated by SEM and EDX analysis. The coated powder was compressed to a cylindrical shape and the samples were sintered by exactly defined microwave process. The mechanical test and electric resistivity measurement were performed.

\section{Experimental}

2.1. Materials. The commercial powder of spherical FeSi particles supplied by Höganäs Corporation was used as the base ferromagnetic material, which is available in the granulometric fraction from $45 \mu \mathrm{m}$ to $150 \mu \mathrm{m}$ [23]. The analytical pure chemicals $\mathrm{Mn}\left(\mathrm{NO}_{3}\right)_{2} \cdot 4 \mathrm{H}_{2} \mathrm{O}$ (99\%, Acros Organic), $\mathrm{Zn}\left(\mathrm{NO}_{3}\right)_{2} \cdot 4 \mathrm{H}_{2} \mathrm{O}$ (98\%, Acros Organic), $\mathrm{Fe}\left(\mathrm{NO}_{3}\right)_{2}$ (99+\%, Acros Organic), and $\mathrm{C}_{6} \mathrm{H}_{8} \mathrm{O}_{7} \cdot \mathrm{H}_{2} \mathrm{O}$ (99.8\% CentralChem) were used to synthesize $\mathrm{Mn}_{0.8} \mathrm{Zn}_{0.2} \mathrm{Fe}_{2} \mathrm{O}_{4}$ ferrite. The equimolar ratio of metal nitrates was dissolved in minimum amount of distilled water. The equimolar ratio of citric acid to the total molar amount of metal nitrates was added to the aqueous solution as a complexing agent during continuous stirring. The $\mathrm{pH}=6$ was adjusted by $\mathrm{NH}_{4} \mathrm{OH}$ (26\% aq., Sigma Aldrich) after total dissolution of citric acid. Roughly $100 \mathrm{~mL}$ of the prepared aqueous solution was heated at $70^{\circ} \mathrm{C}$ for 4 hours until the viscous gel was created. $5 \mathrm{~g}$ of the prepared gel was mixed with $20 \mathrm{~g}$ of FeSi particles and heated at $200^{\circ} \mathrm{C}$ for 12 hours in laboratory dryer. The exothermic reaction and self-propagating combustion process initiated after the creation of xerogel. The $4 \mathrm{wt} \%$ of ferrite was created in the final composite powder agglomerate samples.

2.2. Experimental Procedures. The coated powder was compacted at $600 \mathrm{MPa}$ in cylindrical die without any additives. Density of powder and bulk composite was measured by He-pycnometer AccuPyc II 1340 and calculated from the sample dimensions, respectively. The prism-shaped samples (dimensions $5 \times 4 \times 20 \mathrm{~mm}(w \times h \times l))$ were used to evaluate elastic properties represented by Young modulus $(E)$-Impulse excitation method and software Buzz-o-Sonic and transverse rupture strength (TRS) measured by 3-point bending test using universal testing machine Tiratest 2100 . The cylindrical shaped samples (dimensions of $10 \times 3 \mathrm{~mm}(d \times h))$ were used to measure the hardness tests using TUKKON 1102 hardness tester. The electric resistivity was measured by 4-point probe method using Mitsubishi Loresta AXMCP-T370.

The sintering process was realized in air atmosphere using single mode microwave sintering device (microwave generator $750 \mathrm{~W}$ ). Cylindrical cavity of diameter $28 \mathrm{~mm}$ and of height $80 \mathrm{~mm}$ was used. The sintering temperature profile is shown in Figure 1.

The microstructure and morphology of all the samples were examined by the scanning electron microscope SEM (JEOL JSM-7000F or TESCAN Lyra3) equipped with the energy dispersive X-ray analyzer (EDX) after the carbon coating. The bright-field TEM or STEM images were explored at $200 \mathrm{kV}$ by the transmission electron microscopy TEM (JEOL 2100F). The structural analysis was carried out using X-ray diffraction XRD (X'Pert Pro PanAnalytical) in BraggBrentano geometry, with $\mathrm{CoK} \alpha$ radiation, linear detector, and $\beta$-filter in incident path.

\section{Results and Discussion}

3.1. Synthesis of $\mathrm{Mn}_{0.8} \mathrm{Zn}_{0.2} \mathrm{Fe}_{2} \mathrm{O}_{4}$. The well-described sol-gel synthesis accompanied with the autocombustion process was used for preparation of $\mathrm{Mn}_{0.8} \mathrm{Zn}_{0.2} \mathrm{Fe}_{2} \mathrm{O}_{4}$. The exothermic reaction and decomposition of xerogel result in a creation of the ferrite ash, which shows interesting structure resembling coral (see Figure 2). The synthesized powder particles $\mathrm{Mn}_{0.8} \mathrm{Zn}_{0.2} \mathrm{Fe}_{2} \mathrm{O}_{4}$ were carefully examined with the aim to 


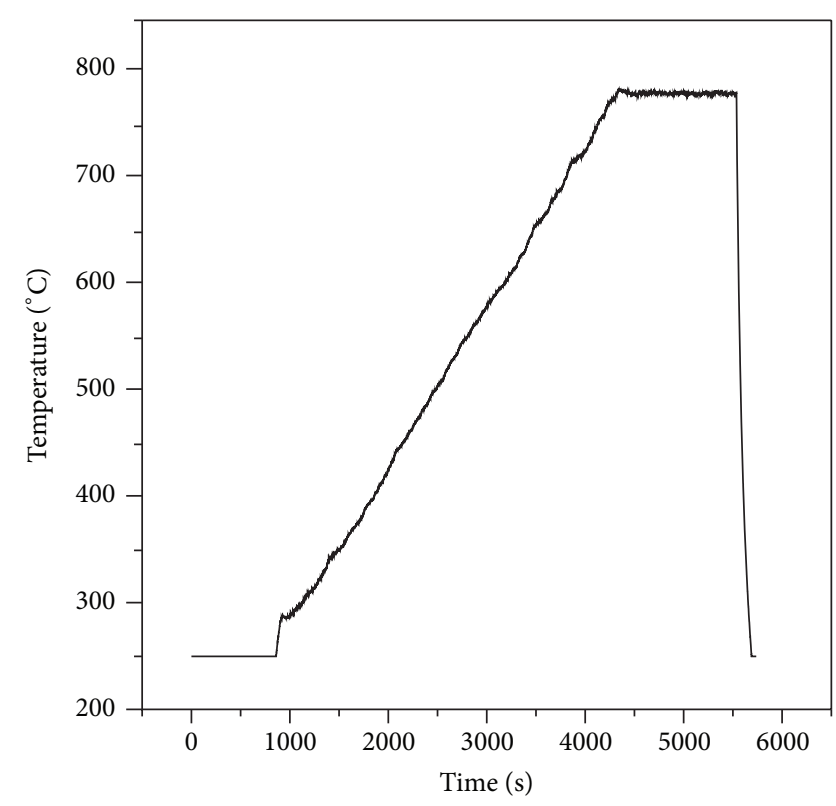

Figure 1: Time-temperature dependence of microwave sintering process.

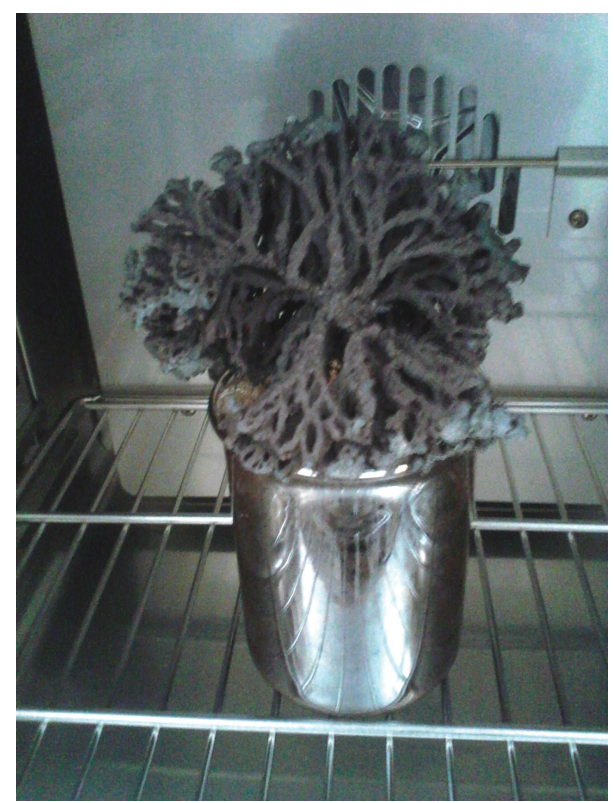

Figure 2: Photograph of $\mathrm{Mn}_{0.8} \mathrm{Zn}_{0.2} \mathrm{Fe}_{2} \mathrm{O}_{4}$ ferrite after autocombustion process.

simplify the latter identification of the MnZn ferrite coating on FeSi substrate. The temperature schedule enabling the complete decomposition process and the ferrite formation was set according to TG-DSC data published by Gabal et al. [24]. The typical thermal decomposition of the prepared precursor with $\mathrm{Zn}$ molar content of 0.2 has been reported in [24] in a temperature range up to $600^{\circ} \mathrm{C}$. The decomposition proceeds through three well-defined TG steps. The most important step has been observed at $200^{\circ} \mathrm{C}$, at which a sharp

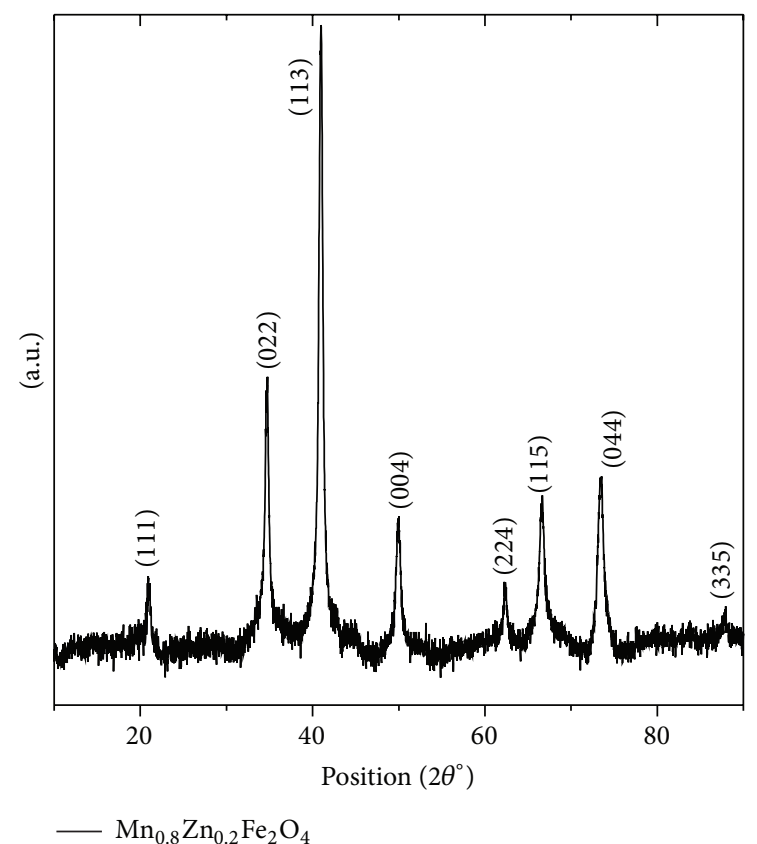

FIGURE 3: XRD pattern of $\mathrm{Mn}_{0.8} \mathrm{Zn}_{0.2} \mathrm{Fe}_{2} \mathrm{O}_{4}$.

exothermic peak accompanied with the main weight loss (78\%) occurs. According to [25], the complete decomposition of the $\mathrm{MnZn}$ ferrite precursor occurs at $340^{\circ} \mathrm{C}$, whereas the nitrate-citrate combustion reaction can be presented as follows:

$$
\begin{aligned}
0.8 \mathrm{Mn} & \left(\mathrm{NO}_{3}\right)_{2} \cdot 4 \mathrm{H}_{2} \mathrm{O}+0.2 \mathrm{Zn}\left(\mathrm{NO}_{3}\right)_{2} \cdot 6 \mathrm{H}_{2} \mathrm{O} \\
+ & 2 \mathrm{Fe}\left(\mathrm{NO}_{3}\right)_{3} \cdot 9 \mathrm{H}_{2} \mathrm{O}+\mathrm{C}_{6} \mathrm{H}_{8} \mathrm{O}_{7} \cdot \mathrm{H}_{2} \mathrm{O} \\
\longrightarrow & \mathrm{Mn}_{0.8} \mathrm{Zn}_{0.2} \mathrm{Fe}_{2} \mathrm{O}_{4}+4 \mathrm{~N}_{2}+6 \mathrm{CO}_{2}+28.4 \mathrm{H}_{2} \mathrm{O} \\
& +5 \mathrm{O}_{2}
\end{aligned}
$$

Note that in our synthesis it was not necessary to heat the $\mathrm{MnZn}$ ferrite up to $340^{\circ} \mathrm{C}$, because the subsequent sintering process of the final composite material FeSi/ $\mathrm{Mn}_{0.8} \mathrm{Zn}_{0.2} \mathrm{Fe}_{2} \mathrm{O}_{4}$ requires the temperature schedule shown in Figure 1 that goes up to $780^{\circ} \mathrm{C}$.

A comparison of the X-ray diffraction pattern of the synthesized powder with the PDF-4 database (1-089-7550) demonstrates a presence of the spinel-type structure only (see Figure 3). The computation of crystal parameters from the diffraction pattern by Rietveld method with structural model based on ICSD (28516) determines the lattice parameter $a=0.8445 \mathrm{~nm}$ and crystalline size about $20 \mathrm{~nm}$ from Scherrer formula [26]. The shape of peaks and broadening of bottom of peaks indicate the presence of highly disordered (amorphous) phase. The crystalline phase in the sample can be indexed as the face centered cubic (fcc) structure corresponding to the inverse spinel structure almost identical to the one reported in [27]. The spinel structure was also verified by the selected area electron diffraction pattern obtained by TEM analysis for the powder sample (see Figure 5(c)). 
TABLE 1: The mechanical properties and electric resistivity of FeSi/ $\mathrm{Mn}_{0.8} \mathrm{Zn}_{0.2} \mathrm{Fe}_{2} \mathrm{O}_{4}$. The columns determine the measured and calculated bulk density, transverse rupture strength (TRS), Young modulus $(E)$, mechanical hardness (HV), and specific electric resistivity.

\begin{tabular}{|c|c|c|c|c|c|c|}
\hline Sample & $\begin{array}{c}\rho(\text { measured bulk }) \\
\left(\mathrm{g} / \mathrm{cm}^{3}\right)\end{array}$ & $\begin{array}{c}\rho(\text { calculated bulk }) \\
\left(\mathrm{g} / \mathrm{cm}^{3}\right)\end{array}$ & $\begin{array}{l}\text { TRS } \\
(\mathrm{MPa})\end{array}$ & $\begin{array}{c}E \\
(\mathrm{GPa}) \\
\end{array}$ & $\begin{array}{l}\mathrm{HV} \\
(\mathrm{GPa})\end{array}$ & $\begin{array}{c}\rho_{e} \\
(\mathrm{Ohm} \cdot \mathrm{cm})\end{array}$ \\
\hline $\mathrm{FeSi} / \mathrm{Mn}_{0.8} \mathrm{Zn}_{0.2} \mathrm{Fe}_{2} \mathrm{O}_{4}$ & $6.534 \pm 0.01$ & 6.069 & $141 \pm 10$ & $121 \pm 0.3$ & $1.4 \pm 0.02$ & $16 \pm 4.5$ \\
\hline $\mathrm{Mn}_{0.8} \mathrm{Zn}_{0.2} \mathrm{Fe}_{2} \mathrm{O}_{4}$ (polycrystalline) [28] & - & - & $195-265$ & $175-177$ & $6-6.7$ & - \\
\hline $\mathrm{Mn}_{0.8} \mathrm{Zn}_{0.2} \mathrm{Fe}_{2} \mathrm{O}_{4}($ size $27-37 \mathrm{~nm})$ [29] & $4.69-5.29$ & - & - & - & - & $3 \cdot 10^{6}$ \\
\hline $\mathrm{Fe}_{3} \mathrm{Si}$ (sintered) $[30]$ & 7.15 & - & - & - & - & $5 \cdot 10^{-5}$ \\
\hline FeSi/phenol-formaldehyde resin [31] & 6.41 & - & 97 & 34 & 0.45 & 0.2 \\
\hline
\end{tabular}

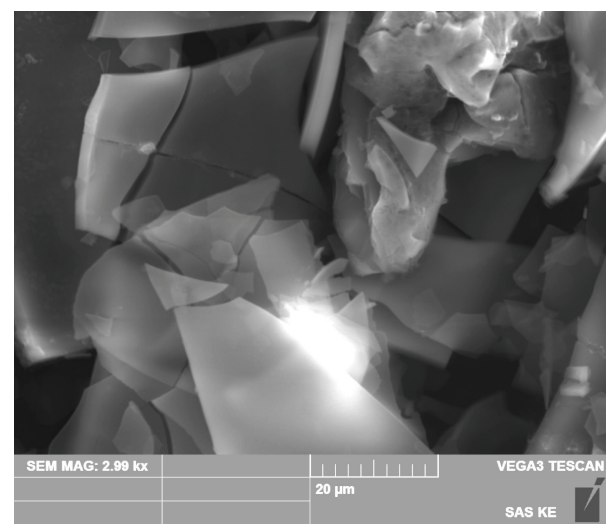

Figure 4: SEM image of $\mathrm{Mn}_{0.8} \mathrm{Zn}_{0.2} \mathrm{Fe}_{2} \mathrm{O}_{4}$.

SEM and TEM of as-burned sample with an extremely fine structure are displayed in Figures 4 and 5. SEM analysis has confirmed sharp edges of the synthesized $\mathrm{MnZn}$ ferrite (Figure 4), while TEM analysis has demonstrated the layered structure (Figure 5(a)). The chemical composition of $\mathrm{MnZn}$ ferrite powder was verified by EDX analysis shown in Figure 5(d). It is quite evident from Figure 5(a) that one layered particle can be seen as a large agglomerate composed of extremely fine nanoparticles. A more detailed analysis of the substructure (zoom Figure 5(b)) verified the formation of small partially ordered nanocrystalline particles with a diameter around $20 \mathrm{~nm}$, which are separated from each other by the amorphous part. The nanocrystalline particles incorporated in amorphous part were also confirmed by XRD pattern of the MnZn ferrite.

\subsection{Preparation of $\mathrm{FeSi} / \mathrm{Mn}_{0.8} \mathrm{Zn}_{0.2} \mathrm{Fe}_{2} \mathrm{O}_{4}$ Composite.} Figure 6(a) shows the SEM image of the original spherical FeSi particles and Figure 6(b) shows the SEM image of the as-prepared $\mathrm{FeSi} / \mathrm{Mn}_{0.8} \mathrm{Zn}_{0.2} \mathrm{Fe}_{2} \mathrm{O}_{4}$ composite, in which the spherical $\mathrm{FeSi}$ particles are linked together through the very fine $\mathrm{MnZn}$ ferrite in order to form large agglomerate. Note that the $\mathrm{MnZn}$ ferrite does not instantaneously produce a continuous coating on $\mathrm{FeSi}$ particles, but one may instead observe a porous layer of the $\mathrm{MnZn}$ ferrite surrounding FeSi particles as illustrated in Figures 7(a) and 7(b). The compaction is responsible for breaking down of the as-prepared ferrite coral structure and, consequently, the continuous coating of the MnZn ferrite surrounding spherical FeSi particles is built up during the compaction process as it is evident from Figures 8(a) and $8(\mathrm{~b})$. It is worthwhile to remark that the fine porous ferrite layers enclosing FeSi particles greatly simplify the compaction process and, thus, the spherical particles may form a dense body. The microwave heating of the final green compact $\mathrm{FeSi} / \mathrm{Mn}_{0.8} \mathrm{Zn}_{0.2} \mathrm{Fe}_{2} \mathrm{O}_{4}$, as described in Section 2.2, was carried out as the final sintering process. It is worthwhile to recall that the very continuous network of the secondary ferrite phase was confirmed from the polished samples of $\mathrm{FeSi} / \mathrm{Mn}_{0.8} \mathrm{Zn}_{0.2} \mathrm{Fe}_{2} \mathrm{O}_{4}$ created after microwave sintering process (see Figures $8(\mathrm{a})$ and $8(\mathrm{~b})$ ). Moreover, the fine structure of the $\mathrm{MnZn}$ ferrite leads to a creation of the composite samples with a very tight arrangement without any significant porosity. It is quite apparent that the compaction procedure has not caused any noticeable deformation of the spherical FeSi particles. The EDX line analysis was employed in order to verify the chemical composition of the final sintered samples. The weight percentages of individual components are displayed in Figure 9 along the line crossing an interface between $\mathrm{MnZn}$ ferrite and spherical FeSi particle, which corresponds to the scale of zoom on the top of Figure 9. The chemical composition at the distances $0.5 \mu \mathrm{m}$ and $3 \mu \mathrm{m}$ of EDX line analysis is specifically mentioned in two charts involved in Figure 9. The weight percentages of individual components at the former distance are in a good accordance with the chemical composition of $\mathrm{Mn}_{0.8} \mathrm{Zn}_{0.2} \mathrm{Fe}_{2} \mathrm{O}_{4}$ ferrite, while the chemical composition at the latter distance points to almost pure FeSi phase. This finding has unambiguously confirmed a successful preparation of FeSi/ $\mathrm{Mn}_{0.8} \mathrm{Zn}_{0.2} \mathrm{Fe}_{2} \mathrm{O}_{4}$ composite.

3.3. Characterization of $\mathrm{FeSi} / \mathrm{Mn}_{0.8} \mathrm{Zn}_{0.2} \mathrm{Fe}_{2} \mathrm{O}_{4}$ Composite. Table 1 shows that the mechanical properties and electric resistivity of the final composite $\mathrm{FeSi} / \mathrm{Mn}_{0.8} \mathrm{Zn}_{0.2} \mathrm{Fe}_{2} \mathrm{O}_{4}$ were significantly affected by the distribution, thickness, and amount of the secondary ferrite phase. The measured and calculated values of the bulk density indicate insignificant porosity in the prepared composite samples. For a comparison, Table 1 enumerates basic characteristics of a few comparative sintered materials. The pure polycrystalline $\mathrm{Mn}_{0.8} \mathrm{Zn}_{0.2} \mathrm{Fe}_{2} \mathrm{O}_{4}$ sample sintered at 1250 or $1300^{\circ} \mathrm{C}$ in the air atmosphere at desired partial pressure of oxygen has TRS from $195 \mathrm{MPa}$ 


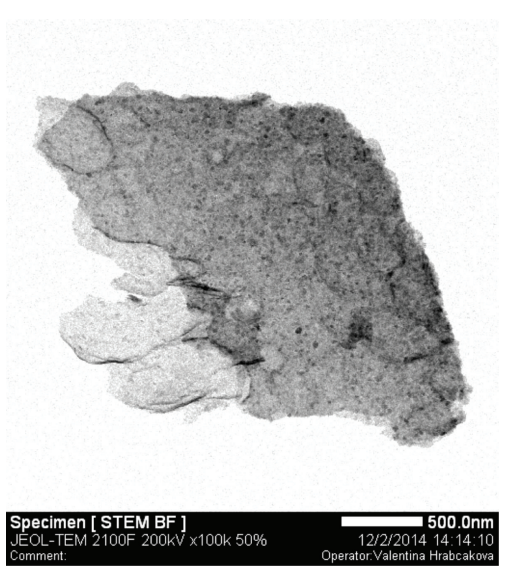

(a)

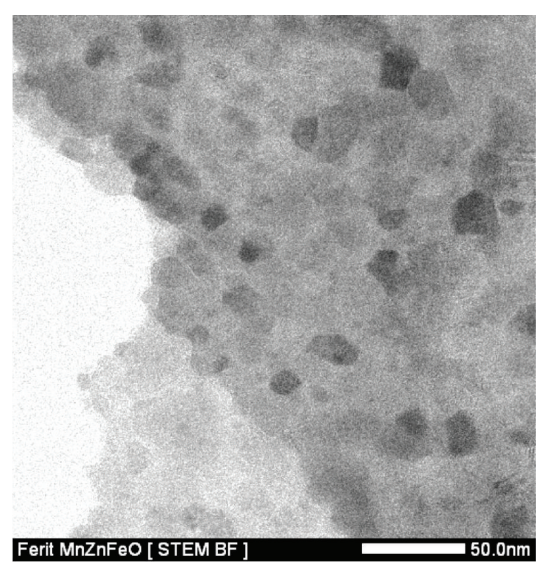

(b)

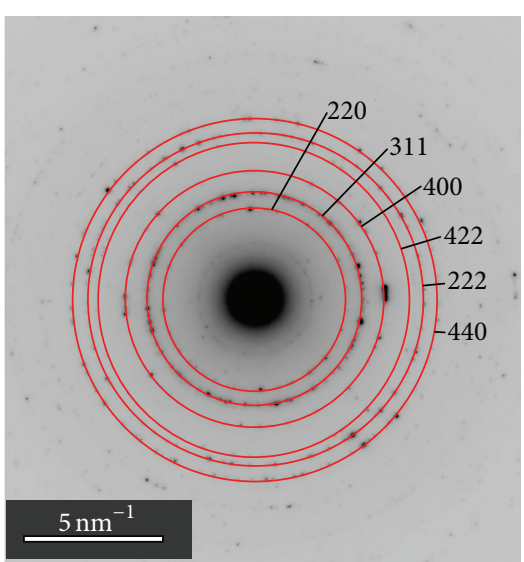

(c)

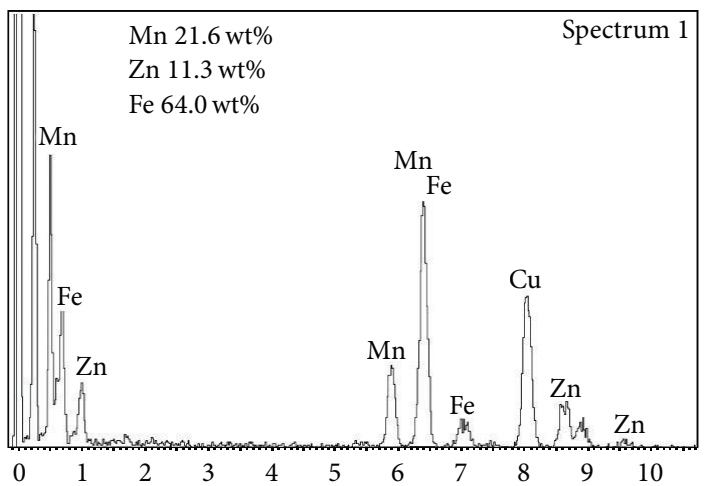

(d)

Figure 5: (a) TEM image of $\mathrm{Mn}_{0.8} \mathrm{Zn}_{0.2} \mathrm{Fe}_{2} \mathrm{O}_{4}$ powder, (b) zoom of $\mathrm{Mn}_{0.8} \mathrm{Zn}_{0.2} \mathrm{Fe}_{2} \mathrm{O}_{4}$ powder, (c) diffractogram, and (d) EDX analysis.

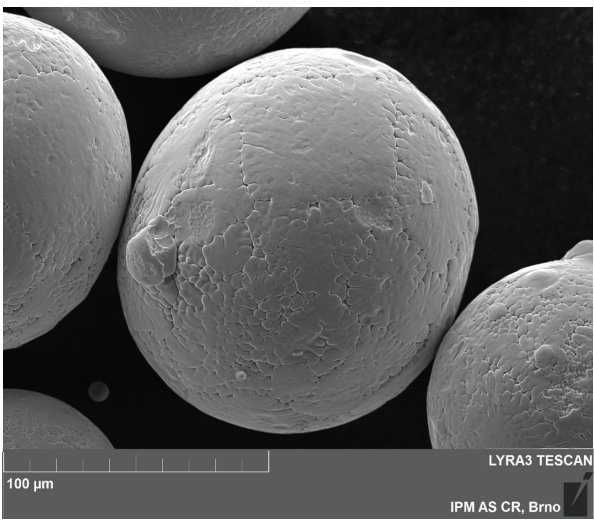

(a)

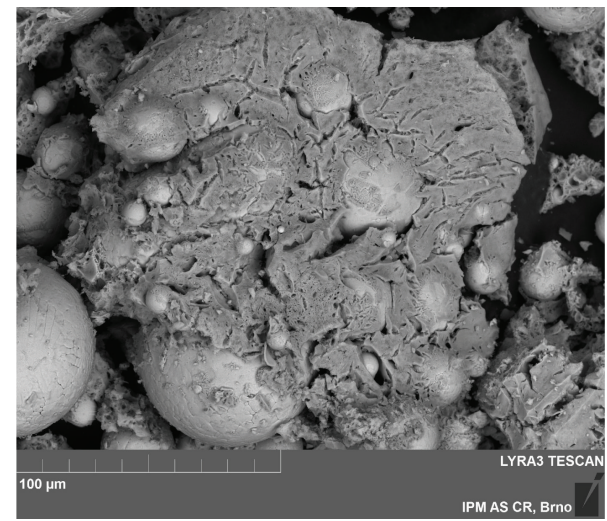

(b)

Figure 6: SEM images from (a) the original FeSi spherical powder (97\% Fe and 3\% Si); (b) the agglomerate of FeSi particles embedded in $\mathrm{Mn}_{0.8} \mathrm{Zn}_{0.2} \mathrm{Fe}_{2} \mathrm{O}_{4}$ ferrite.

to $265 \mathrm{MPa}$ and Young modulus from $175 \mathrm{GPa}$ to $177 \mathrm{GPA}$, which indicate very hard ( $\mathrm{HV}$ approximately $6 \mathrm{GPa})$ and brittle material. It is of technological importance that the measured values of mechanical hardness, transverse rupture strength, and Young modulus for the FeSi/Mn ${ }_{0.8} \mathrm{Zn}_{0.2} \mathrm{Fe}_{2} \mathrm{O}_{4}$ composite are quite superior with respect to the ones of the analogous composite involving the same FeSi powder and the phenol-formaldehyde resin as the insulating coating (cf. the first and the last row in Table 1). In addition, it is quite clear from Table 1 that all the mechanical properties of $\mathrm{FeSi} / \mathrm{Mn}_{0.8} \mathrm{Zn}_{0.2} \mathrm{Fe}_{2} \mathrm{O}_{4}$ are comparable (of the same order of magnitude) with the basic characteristics of the pure sintered $\mathrm{Mn}_{0.8} \mathrm{Zn}_{0.2} \mathrm{Fe}_{2} \mathrm{O}_{4}$ ferrite. The homogeneous distribution of the insulating coating based on the $\mathrm{MnZn}$ 


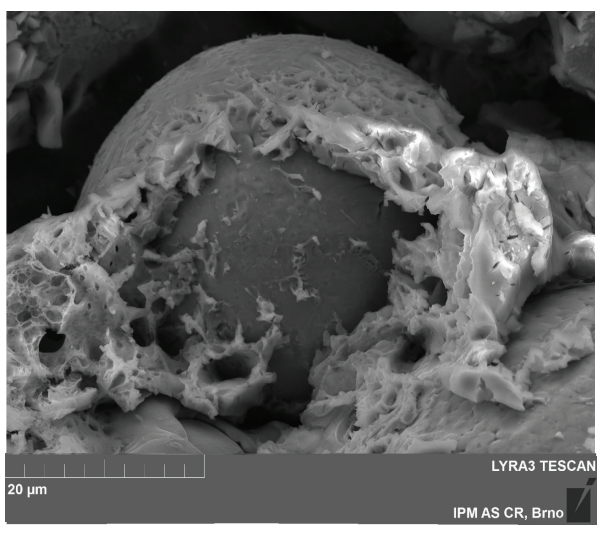

(a)

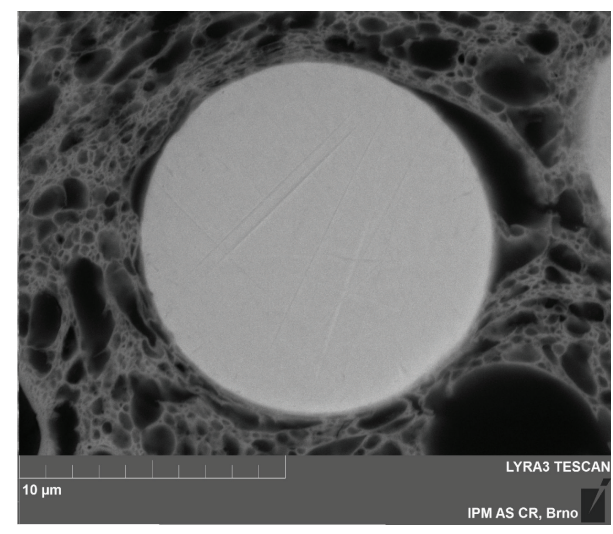

(b)

FIgURE 7: SEM images from (a) the individual FeSi particle covered by $\mathrm{Mn}_{0.8} \mathrm{Zn}_{0.2} \mathrm{Fe}_{2} \mathrm{O}_{4}$ ferrite; (b) the cross section of FeSi particle surrounded by $\mathrm{Mn}_{0.8} \mathrm{Zn}_{0.2} \mathrm{Fe}_{2} \mathrm{O}_{4}$ ferrite.

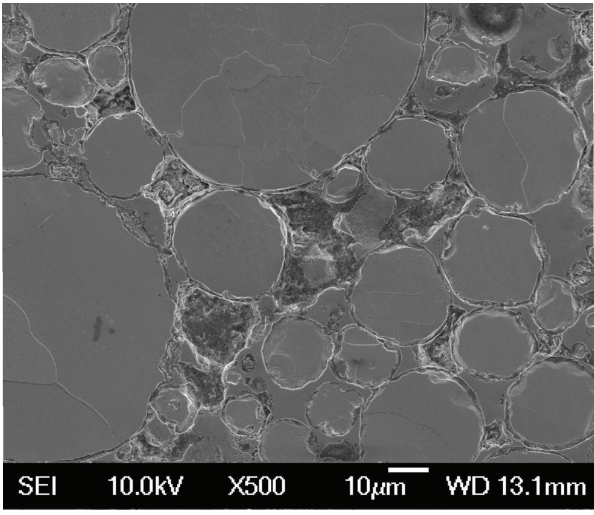

(a)

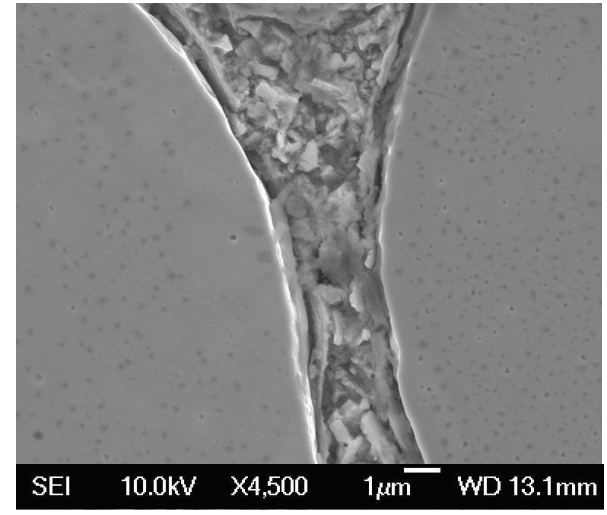

(b)

FIGURE 8: (a) and (b) SEM images displaying a cross section from the sintered FeSi/ $\mathrm{Mn}_{0.8} \mathrm{Zn}_{0.2} \mathrm{Fe}_{2} \mathrm{O}_{4}$.

ferrite manifests itself also through a sufficiently high specific electric resistivity of the $\mathrm{FeSi} / \mathrm{Mn}_{0.8} \mathrm{Zn}_{0.2} \mathrm{Fe}_{2} \mathrm{O}_{4}$ composite, which is almost two orders of magnitude greater than the specific electric resistivity of the FeSi/phenol-formaldehyde resin composite. This result would suggest that the prepared $\mathrm{FeSi} / \mathrm{Mn}_{0.8} \mathrm{Zn}_{0.2} \mathrm{Fe}_{2} \mathrm{O}_{4}$ composite could represent the improved SMC due to lower eddy current losses at medium and higher frequencies, which will be significantly hindered by a rather high specific electric resistivity.

\section{Conclusion}

The novel composite material was designed from the spherical $\mathrm{FeSi}$ particles and the soft magnetic ferrite $\mathrm{Mn}_{0.8} \mathrm{Zn}_{0.2} \mathrm{Fe}_{2} \mathrm{O}_{4}$ with the inverse spinel structure. The aforementioned $\mathrm{MnZn}$ ferrite was synthesized by the sol-gel autocombustion method from the nitrate-citrate aqueous solution. The composite powder coated by the MnZn ferrite was prepared in the form of large agglomerates, which were used for the subsequent compaction and final sintering of green compacts. The inverse spinel structure of the prepared $\mathrm{Mn}_{0.8} \mathrm{Zn}_{0.2} \mathrm{Fe}_{2} \mathrm{O}_{4}$ was confirmed by XRD analysis. SEM images have enabled us to identify very fine structure of the prepared powder with sharp edges. TEM analysis has evidenced the layered structure of the pure MnZn ferrite and it has also visualized large agglomerates composed of fine nanoparticles of approximate size $20 \mathrm{~nm}$.

It has been found that the fine porous MnZn ferrite structure provides a very convenient secondary phase during the compaction process, because tight arrangement of spherical FeSi particles onto dense body without any significant porosity is possible after overall breaking down of the porous $\mathrm{MnZn}$ ferrite structure. It turns out that the mechanical properties of the final FeSi/ $\mathrm{Mn}_{0.8} \mathrm{Zn}_{0.2} \mathrm{Fe}_{2} \mathrm{O}_{4}$ composite are quite superior with respect to that ones of the analogous composites, in which the organic binder (mostly phenol-formaldehyde resin) is used as the insulating coating instead of the MnZn ferrite. The homogeneous distribution of the insulating coating based on the MnZn ferrite is reflected in a rather high specific electric resistivity of the FeSi $/ \mathrm{Mn}_{0.8} \mathrm{Zn}_{0.2} \mathrm{Fe}_{2} \mathrm{O}_{4}$ composite, which indicates perspective application of this SMC material at medium and high frequencies due to a substantial reduction of relevant eddy current losses. According to this, the investigation of basic 


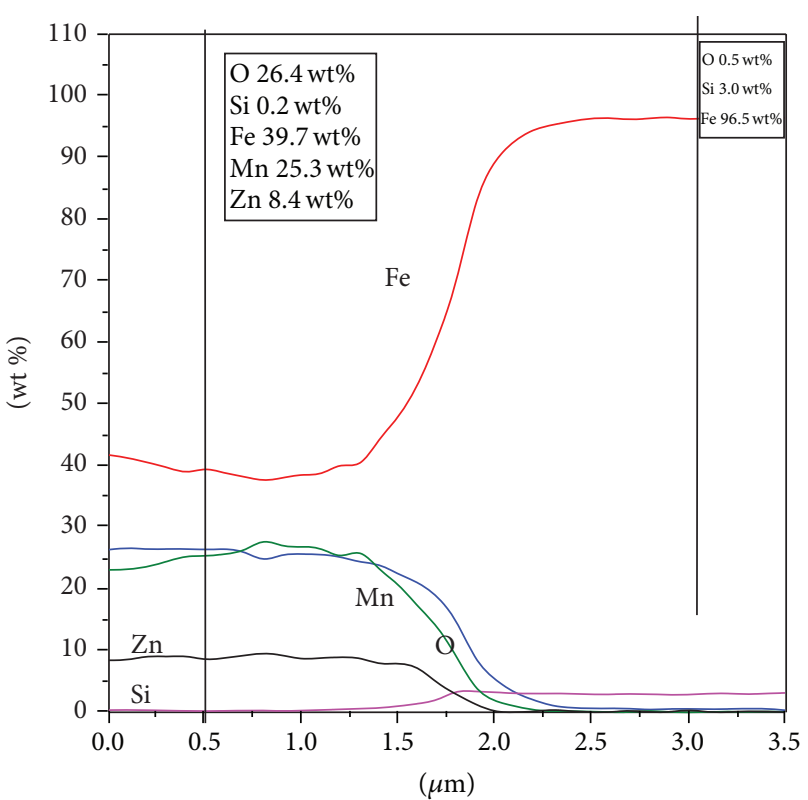

(a)

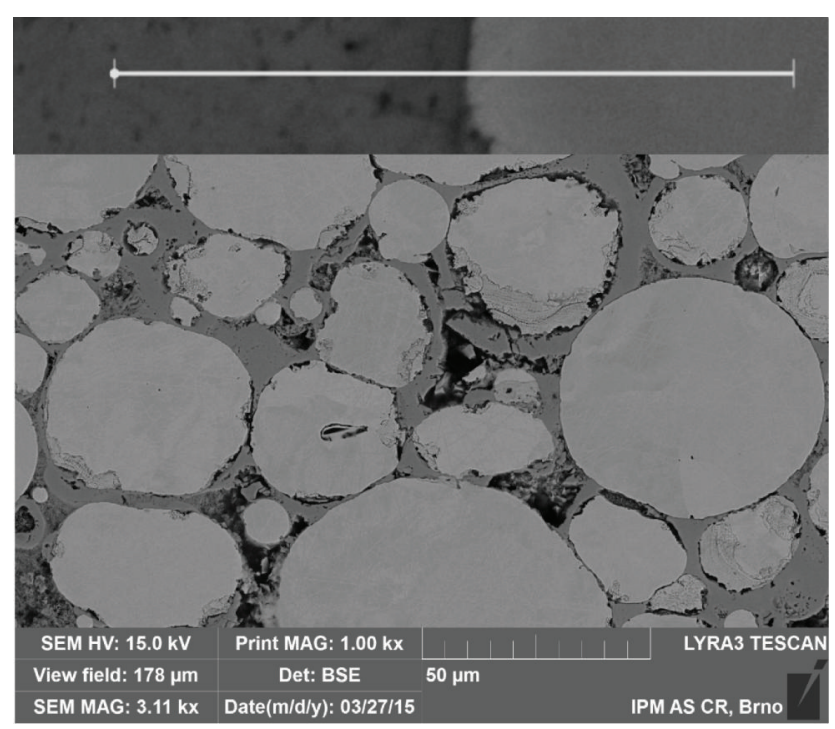

(b)

Figure 9: EDX line analysis of the final sintered sample FeSi/ $\mathrm{Mn}_{0.8} \mathrm{Zn}_{0.2} \mathrm{Fe}_{2} \mathrm{O}_{4}$ supplemented with two charts involving the chemical composition at the distances $0.5 \mu \mathrm{m}$ and $3 \mu \mathrm{m}$ according to the scale of zoom located on the top.

magnetic characteristics and their optimization represents a challenging task for our future work.

\section{Conflict of Interests}

The authors declare that there is no conflict of interests regarding the publication of this paper.

\section{Acknowledgments}

This work was supported in part by the projects "the progressive technology for preparation of microcomposite materials for electrotechnology," ITMS 26220220105, and by the Scientific Grant Agency of the Ministry of Education of Slovak Republic and the Slovak Academy of Sciences, Project VEGA 2/0185/15. This work was also realized in CEITEC (Central European Institute of Technology) with research infrastructure supported by the Project CZ.1.05/1.1.00/02.0068 financed from European Regional Development Fund and Czech Science Foundation P108/11/1350.

\section{References}

[1] H. Shokrollahi and K. Janghorban, "Soft magnetic composite materials (SMCs)," Journal of Materials Processing Technology, vol. 189, no. 1-3, pp. 1-12, 2007.

[2] B. Ślusarek, B. Jankowski, K. Sokalski, and J. Szczygłowski, "Characteristics of power loss in soft magnetic composites a key for designing the best values of technological parameters," Journal of Alloys and Compounds, vol. 581, pp. 699-704, 2013.

[3] S. Wu, A. Sun, W. Xu et al., "Iron-based soft magnetic composites with $\mathrm{Mn}-\mathrm{Zn}$ ferrite nanoparticles coating obtained by solgel method," Journal of Magnetism and Magnetic Materials, vol. 324, no. 22, pp. 3899-3905, 2012.

[4] A. H. Taghvaei, H. Shokrollahi, and K. Janghorban, "Magnetic and structural properties of iron phosphate-phenolic soft magnetic composites," Journal of Magnetism and Magnetic Materials, vol. 321, no. 23, pp. 3926-3932, 2009.

[5] M. Streckova, R. Bures, M. Faberova, L. Medvecky, J. Fuzer, and P. Kollar, "A comparison of soft magnetic composites designed from different ferromagnetic powders and phenolic resins," Chinese Journal of Chemical Engineering, 2014.

[6] B. V. Neamţu, O. Geoffroy, I. Chicinaş, and O. Isnard, "AC magnetic properties of the soft magnetic composites based on Supermalloy nanocrystalline powder prepared by mechanical alloying," Materials Science and Engineering B: Solid-State Materials for Advanced Technology, vol. 177, no. 9, pp. 661-665, 2012.

[7] H. Kronmuller, Handbook of Magnetism and Advanced Magnetic Materials, Wiley, 2007.

[8] Y. Mastai, "Crystalization in spinel ferrite nanoparticles," in Advances in Crystallization Processes, chapter 14, InTech, 2012, http://cdn.intechopen.com/pdfs/36363/InTech-Crystalization in_spinel_ferrite_nanoparticles.pdf.

[9] M. P. Gonzalez-Sandoval, A. M. Beesley, M. Miki-Yoshida, L. Fuentes-Cobas, and J. A. Matutes-Aquino, "Comparative study of the microstructural and magnetic properties of spinel ferrites obtained by co-precipitation," Journal of Alloys and Compounds, vol. 369, no. 1-2, pp. 190-194, 2004.

[10] J. Wang, F. Ren, B. Jia, and X. Liu, "Solvothermal synthesis and characterization of $\mathrm{NiFe}_{2} \mathrm{O}_{4}$ nanospheres with adjustable sizes," Solid State Communications, vol. 150, no. 25-26, pp. 1141-1144, 2010.

[11] Z. Zhang, Y. Liu, G. Yao, G. Zu, X. Zhang, and J. Ma, "Solid-state reaction synthesis of $\mathrm{NiFe}_{2} \mathrm{O}_{4}$ nanoparticles by optimizing the synthetic conditions," Physica E: Low-Dimensional Systems and Nanostructures, vol. 45, pp. 122-129, 2012.

[12] P. Sivakumar, R. Ramesh, A. Ramanand, S. Ponnusamy, and C. Muthamizhchelvan, "Synthesis, studies and growth mechanism of ferromagnetic $\mathrm{NiFe}_{2} \mathrm{O}_{4}$ nanosheet," Applied Surface Science, vol. 258, no. 17, pp. 6648-6652, 2012.

[13] E. Darezereshki, "One-step synthesis of hematite $\left(\alpha-\mathrm{Fe}_{2} \mathrm{O}_{3}\right)$ nano-particles by direct thermal-decomposition of maghemite," Materials Letters, vol. 65, no. 4, pp. 642-645, 2011. 
[14] J. L. Gunjakar, A. M. More, K. V. Gurav, and C. D. Lokhande, "Chemical synthesis of spinel nickel ferrite $\left(\mathrm{NiFe}_{2} \mathrm{O}_{4}\right)$ nanosheets," Applied Surface Science, vol. 254, pp. 5844-5848, 2008.

[15] R. Raeisi Shahraki, M. Ebrahimi, S. A. Seyyed Ebrahimi, and S. M. Masoudpanah, "Structural characterization and magnetic properties of superparamagnetic zinc ferrite nanoparticles synthesized by the coprecipitation method," Journal of Magnetism and Magnetic Materials, vol. 324, no. 22, pp. 3762-3765, 2012.

[16] S. A. Seyyed Ebrahimi, S. M. Masoudpanah, H. Amiri, and M. Yousefzadeh, "Magnetic properties of MnZn ferrite nanoparticles obtained by SHS and sol-gel autocombustion techniques," Ceramics International, vol. 40, no. 5, pp. 6713-6718, 2014.

[17] W. J. Wang, C. G. Zang, and Q. J. Jiao, "Synthesis, structure and electromagnetic properties of $\mathrm{Mn}-\mathrm{Zn}$ ferrite by sol-gel combustion technique," Journal of Magnetism and Magnetic Materials, vol. 349, pp. 116-120, 2014.

[18] B. S. Zlatkov, N. S. Mitrović, M. V. Nikolić et al., "Properties of $\mathrm{MnZn}$ ferrites prepared by powder injection molding technology," Materials Science and Engineering B, vol. 175, no. 3, pp. 217222, 2010.

[19] G. Kogias, V. Tsakaloudi, P. van der Valk, and V. Zaspalis, "Improvement of the properties of MnZn ferrite power cores through improvements on the microstructure of the compacts," Journal of Magnetism and Magnetic Materials, vol. 324, no. 2, pp. 235-251, 2012.

[20] L. Yang, G. Xi, and J. Liu, "MnZn ferrite synthesized by sol-gel auto-combustion and microwave digestion routes using spent alkaline batteries," Ceramics International, vol. 41, no. 3, pp. 3555-3560, 2015.

[21] S. Kumar, T. J. Shinde, and P. N. Vasambekar, "Microwave synthesis and characterization of nanocrystalline Mn-Zn ferrites," Advanced Materials Letters, vol. 4, no. 5, pp. 373-377, 2013.

[22] L. Zhenyu, X. Guangliang, and Z. Yalin, "Microwave assisted low temperature synthesis of MnZn ferrite nanoparticles," Nanoscale Research Letters, vol. 2, no. 1, pp. 40-43, 2007.

[23] Hoganas datasheet, https://www.hoganas.com/.

[24] M. A. Gabal, R. S. Al-luhaibi, and Y. M. Al Angari, "Recycling spent zinc-carbon batteries through synthesizing nanocrystalline Mn-Zn ferrites," Powder Technology, vol. 258, pp. 32-37, 2014.

[25] M. A. Gabal and Y. M. Al Angari, "Low-temperature synthesis of nanocrystalline $\mathrm{NiCuZn}$ ferrite and the effect of $\mathrm{Cr}$ substitution on its electrical properties," Journal of Magnetism and Magnetic Materials, vol. 322, no. 20, pp. 3159-3165, 2010.

[26] H. P. Klug and L. E. Alexander, X-ray Diffraction Procedures for Polycrystalline and Amorphous Materials, Wiley, New York, NY, USA, 1997.

[27] S. Kumar, S. N. Dolia, and R. K. Singhal, "Application of Rietveld method to the structural characteristics of some bulk and nanocrystalline materials," AIP Conference Proceedings, vol. 1391, pp. 65-67, 2011.

[28] T. Tanaka, "Young's and shear moduli, hardness and bending strength of polycrystalline Mn-Zn ferrites," Japanese Journal of Applied Physics, vol. 14, no. 12, pp. 1897-1901, 1975.

[29] M.-R. Syue, F.-J. Wei, C.-S. Chou, and C.-M. Fu, "Magnetic, dielectric, and complex impedance properties of nanocrystalline Mn-Zn ferrites prepared by novel combustion method," Thin Solid Films, vol. 519, no. 23, pp. 8303-8306, 2011.

[30] http://www.pramiz.com/softm.html.

[31] M. Strečková, J. Füzer, L. Kobera et al., "A comprehensive study of soft magnetic materials based on FeSi spheres and polymeric resin modified by silica nanorods," Materials Chemistry and Physics, vol. 147, no. 3, pp. 649-660, 2014. 

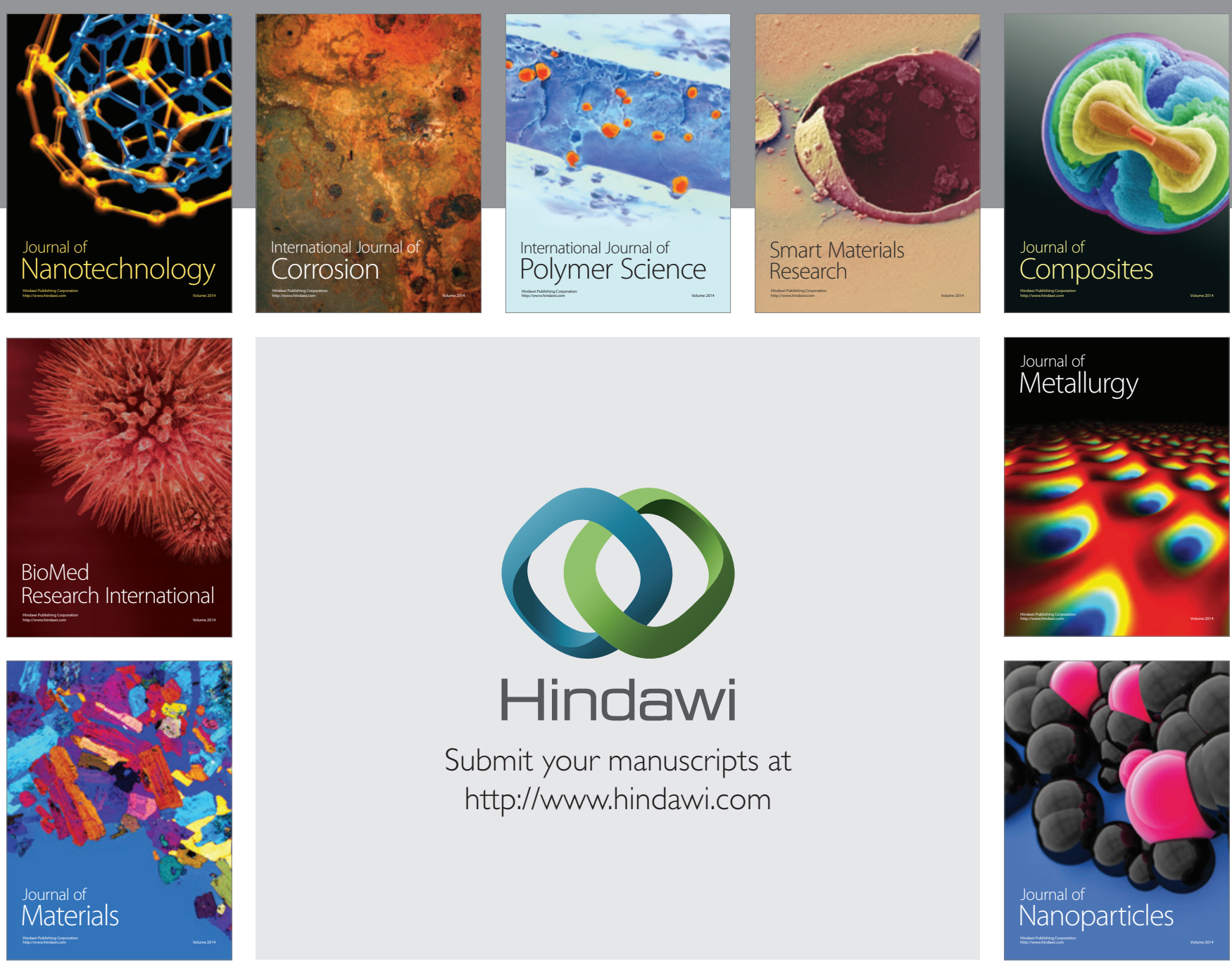

Submit your manuscripts at http://www.hindawi.com
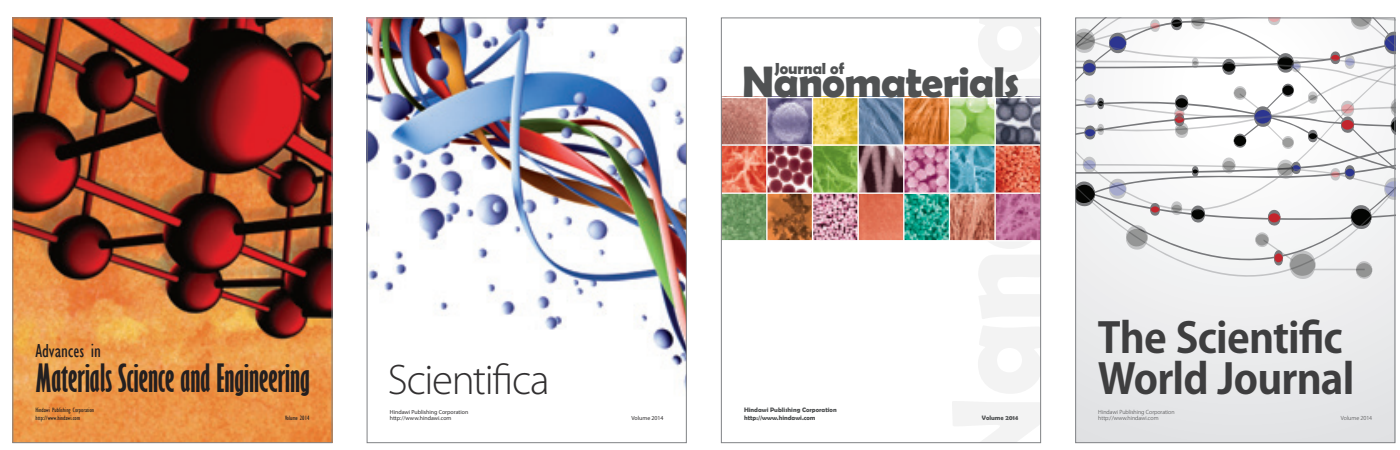

\section{The Scientific World Journal}
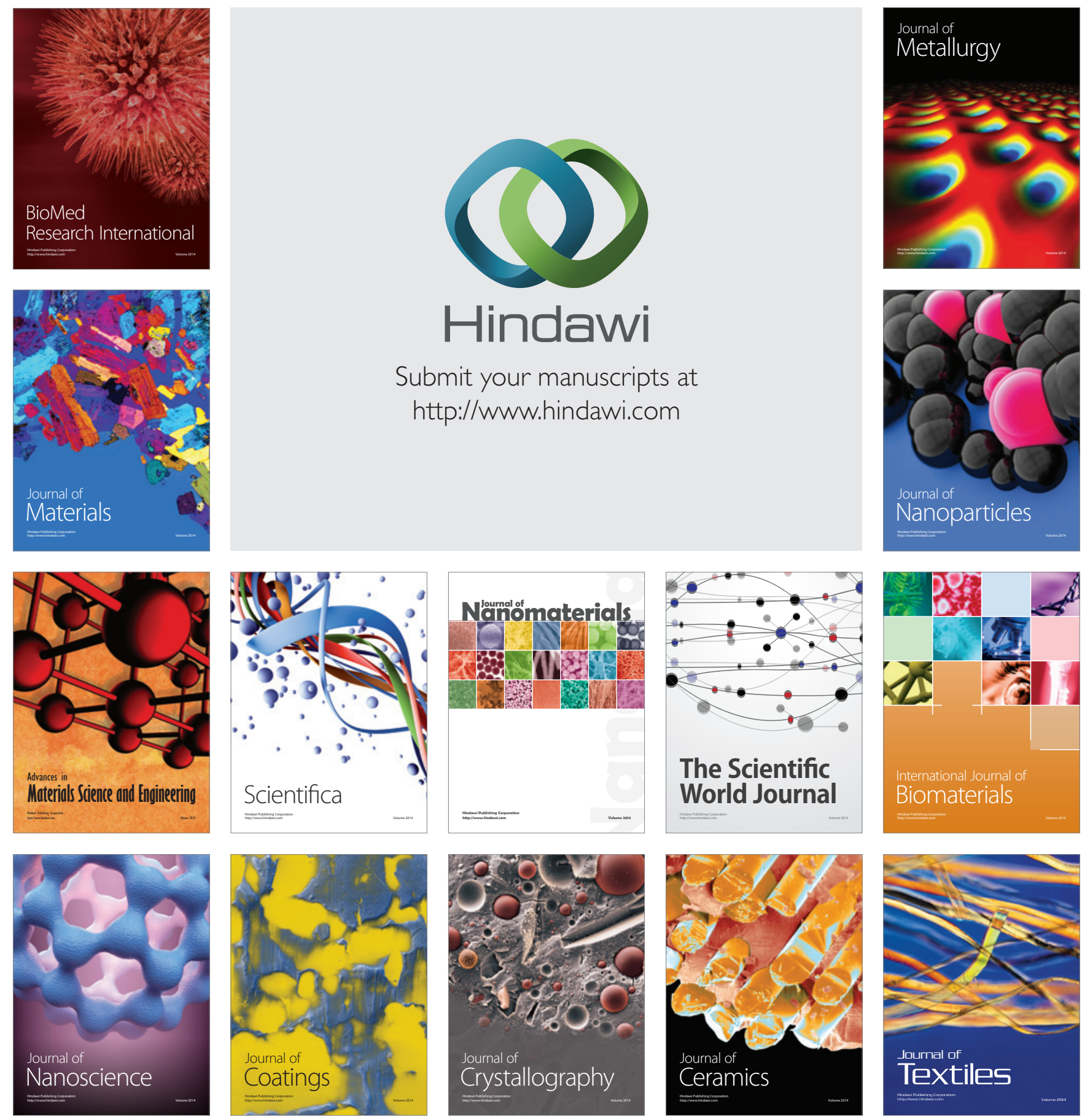